\title{
Связь техногенной сейсмичности с солнечно-лунными циклами на примере Хибинских рудников
}

\author{
Жирова А.М., Жиров Д.В.
}

Геологический институт КНЦРАН, Anamumbl,anzhelaz@geoksc.apatity.ru; zhirov@geoksc.apatity.ru

Аннотация. Цель данной работы состоит в установления связи пространственно-временных закономерностей в распределениях сейсмических событий с гравитационным воздействием Луны и Солнца. Для анализа этих процессов использованы длительные ряды достоверных наблюдательных данных, как для сейсмических событий, так и для фазовых изменений Луны.

Ключевые слова: временные ряды сейсмичности, гравитационное воздействие Луны и Солнца, фазовые изменения Луны.

\section{Relation of technogenic seismicity with solar-lunar cycles on the example of the Khibiny mines}

\author{
Zhirova A.M., Zhirov D.V. \\ Geological institute KSCRAS, Apatity,anzhelaz@geoksc.apatity.ru; zhirov@geoksc.apatity.ru
}

Abstract. The purpose of this work is to determine the connection of spatial and temporal patterns in the distributions of seismic events with the gravitational influence of the Moon and Sun. Long series of reliable observational data, both for seismic events and for phase changes of the Moon, are used to analyze these processes.

Key words: Time series of seismicity, gravitational influence of the Moon and Sun, Moon phase changes.

\section{Введение}

В статье приводятся результаты исследования связи сейсмичности в районе действующих рудников Кольского региона с солнечно-лунным приливным воздействием. Работа базируется на данных сейсмических событий для рудника Расвумчорр за период с 8 апреля 2001 г. по 31 июля 2019 г. и Объединённого Кировского рудника за период с 7 июня 1987 г. по 31 июля 2019 г., а также сведений о фазах Луны для этих же периодов.

Построены временные ряды сейсмичности - количества событий и энергия, приведённые к календарным суткам. На основе имеющихся данных выполнен анализ распределения количества и энергии сейсмических событий по дням синодических месяцев.

\section{Исходные данные и методика работы}

Влияние солнечно-лунных приливов на техногенную сейсмичность рассмотрено на примере рудника Расвумчорр (РР) и Объединённого Кировского рудника (ОКР) АО Апатит, характеризующихся общностью черт геологического строения, тектоники, масштаба и технологии добычи. Оба расположены в пределах пояса конических интрузий фоидолитов в крупнейшем в мире Хибинском щелочном массиве (ХМ). Их период эксплуатации насчитывает несколько десятилетий (около 90 лет для ОКР и более 60 для РР). Разработка месторождений ведётся одним предприятием с применением одних и тех же технологий и режима производства. Различия в геологии рудников заключаются в относительном повороте структур месторождений на 15-20 вокруг геометрического центра ХМ. Постановка задачи в таком ракурсе позволит оценить однородность / неоднородность воздействия солнечно-лунных приливов на локальные, незначительно различающиеся между собой участки.

Методически работа была построена в приведенной ниже последовательности. Регистрационные каталоги сейсмической активности, использованные ранеe (Zhirova, Zhirov, 2019), дополнены сейсмическими материалами, из которых исключены все данные о взрывах и оставлены только естественные сейсмические события: для рудника РР это период с 8 апреля 2001 г. по 31 июля 2019 г. и для рудника ОКР - с 7 июня 1987 г. по 31 июля 2019 г. Изучаемые временные ряды сейсмичности были разбиты на интервалы времени длительностью 29 дней, равные с точностью до 
полусуток синодическому месяцу. В соответствии с лунным календарем (Климишин, 1985), были получены сведения о фазах Луны. Для каждого лунного дня рассчитаны: количество событий, а также суммарная сейсмическая энергия ( $\operatorname{Lg}$ Дж), приходящаяся на каждый лунный день. Данные об основных явлениях в движении Луны взяты из таблиц расчётных моментов прохождений Луной перигея и апогея орбиты, полученных на основе полуаналитической теории движения Луны ELP 2000-82 и каталога (Астрономические ..., 2012).

\section{Результаты}

\section{1. Временные ряды сейсмичности}

На основе данных регистрации сейсмичности в районе рудника РР, получены следующие временные ряды: график зависимости количества событий от даты (рис. 1) и график зависимости энергии (логарифм суммы энергий) событий от даты (рис. 2). По рисунку 1 заметно, что в течение всего исследуемого временного периода число зарегистрированных сейсмический событий в основном не превышало 100 событий за сутки. Количество же суток с аномально высокой сейсмичностью (превышающих 100 событий в сутки) - не более десяти. Максимальные значения энергии сейсмических событий (см. рис. 2), происходившие в изучаемый временной интервал, не превосходили 2142270100 Дж, что соответствует 9.3 логарифма Дж энергии.

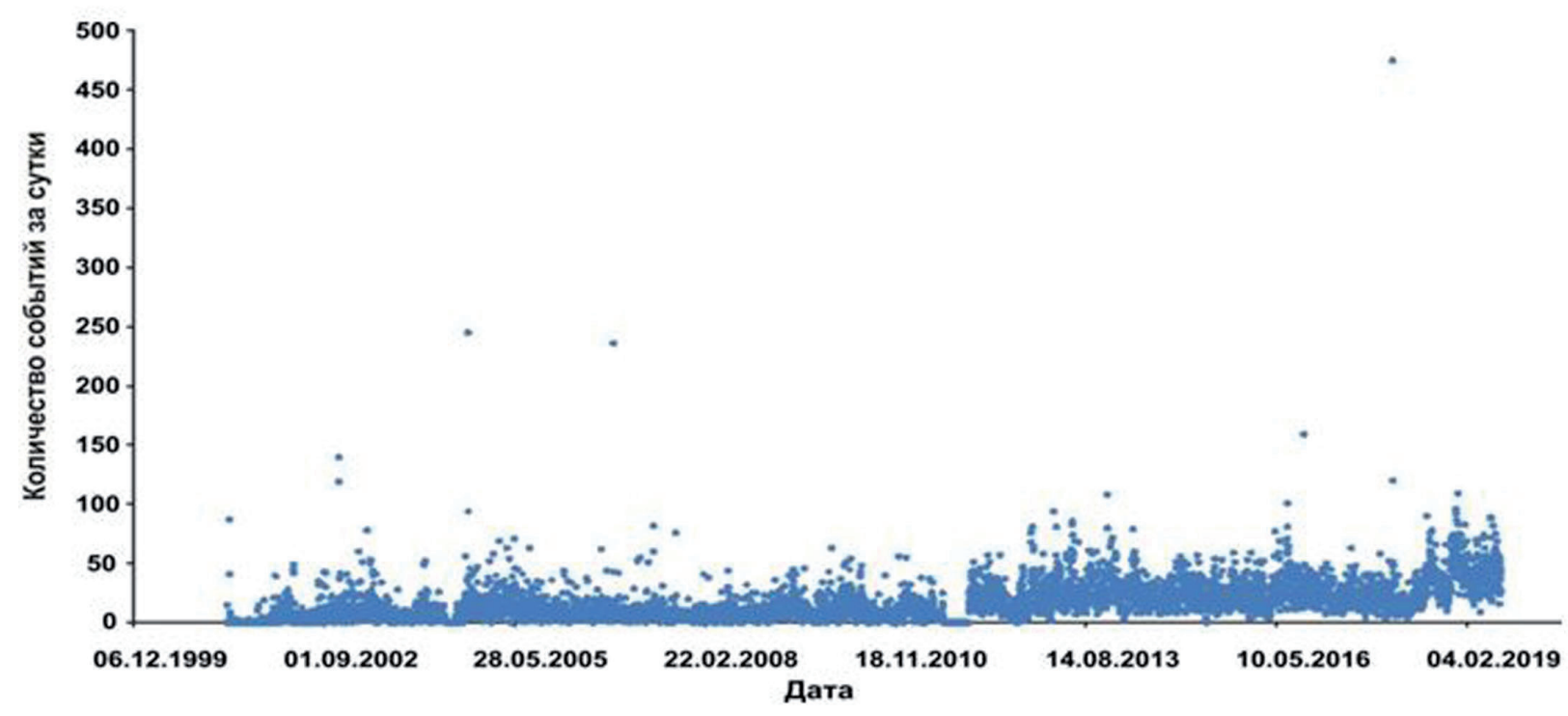

Рис. 1. Временной ряд сейсмичности (количества событий в сутки) в районе рудника РР.

Fig. 1. Time series of seismicity (number of events per day) in the RM mine area.

Аналогичные графики временных рядов получены для рудника ОКР (рис. 3 и 4). Рисунок 3 показывает, что, несмотря на то, что основная масса событий также находится в пределах 100 в сутки, тем не менее, дней с повышенной сейсмичностью (превышающий 100 событий) значительно больше в сравнении с РP (свыше 300 суток). Превышение количества таких событий составляет 30-кратное, а превышение анализируемого временного периода всего в 2 раза. По рисунку 4 заметно, что максимальные значения энергии сейсмических событий не превосходили 24721247000 Дж, что соответствует 10.4 логарифма Дж энергии.

\section{2. Распределение сейсмических событий по дням синодического месяца}

В результате анализа имеющихся данных построены графики распределения количества и энергии сейсмических событий по дням синодического месяца (рис. 5-6). Пик энергии и количества сейсмических событий для ОКР приходится на период перед полнолунием и новолунием, а спад - 


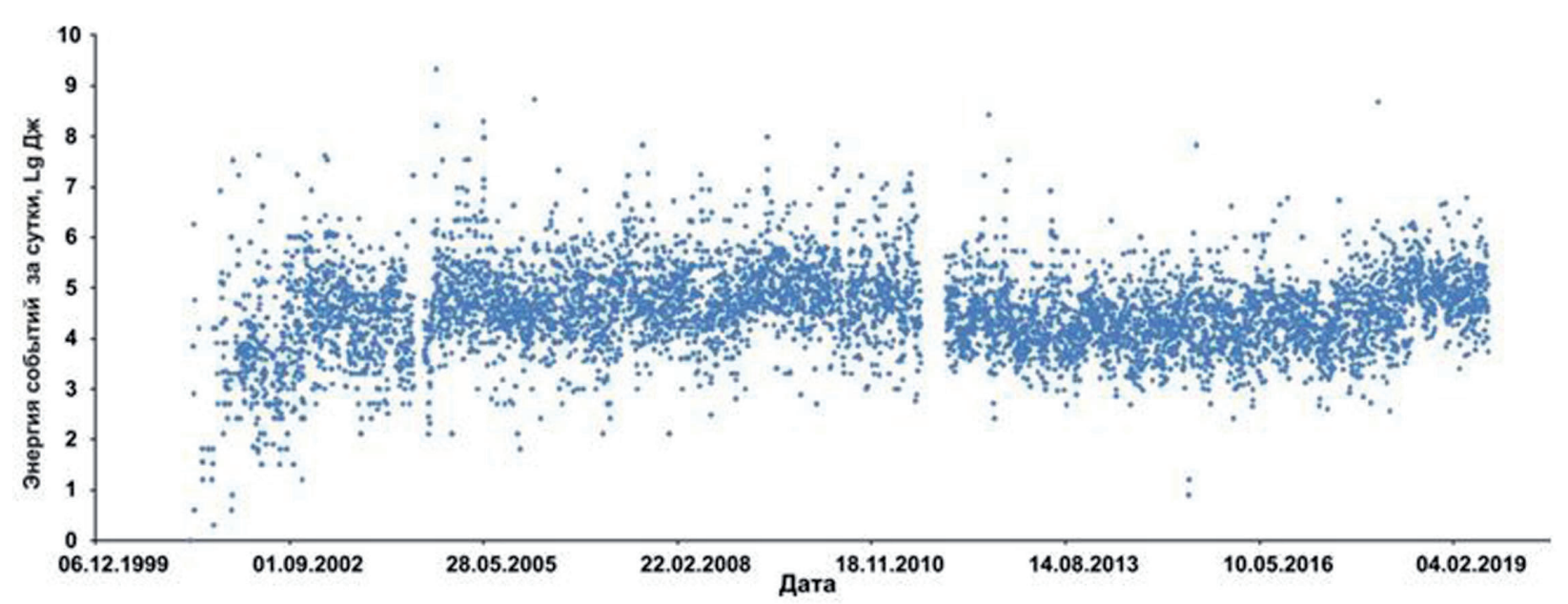

Рис. 2. Временной ряд сейсмичности (энергия событий в сутки) в районе рудника РР.

Fig. 2. Time series of seismicity (energy of events per day) in the RM mine area.

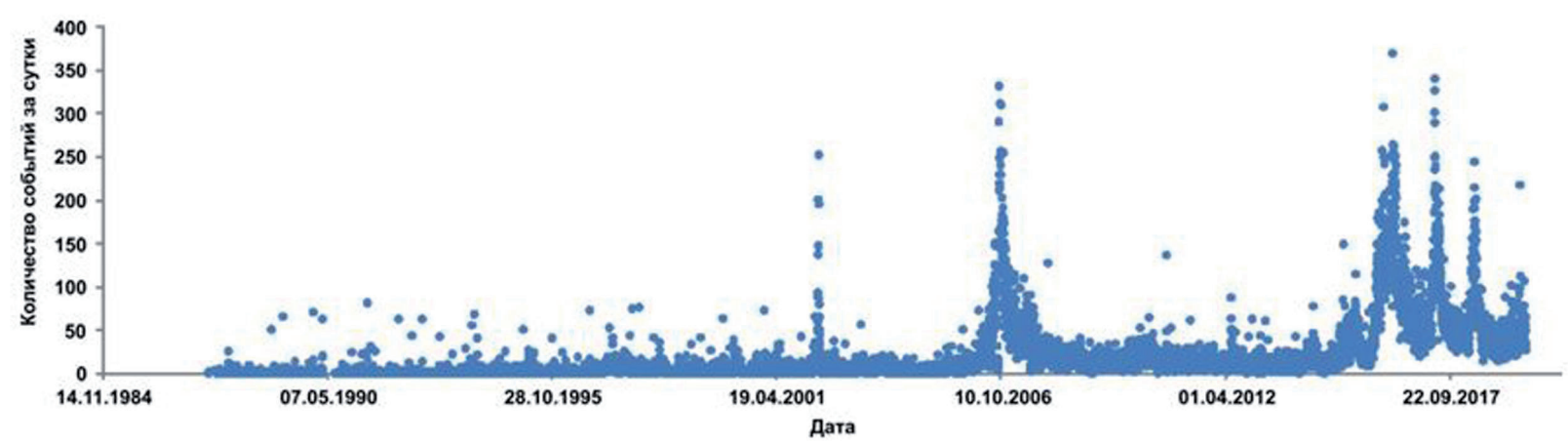

Рис. 3. Временной ряд сейсмичности (количества событий в сутки) в районе рудника ОКР.

Fig. 3. Time series of seismicity (number of events per day) in the area of the OKR mine.

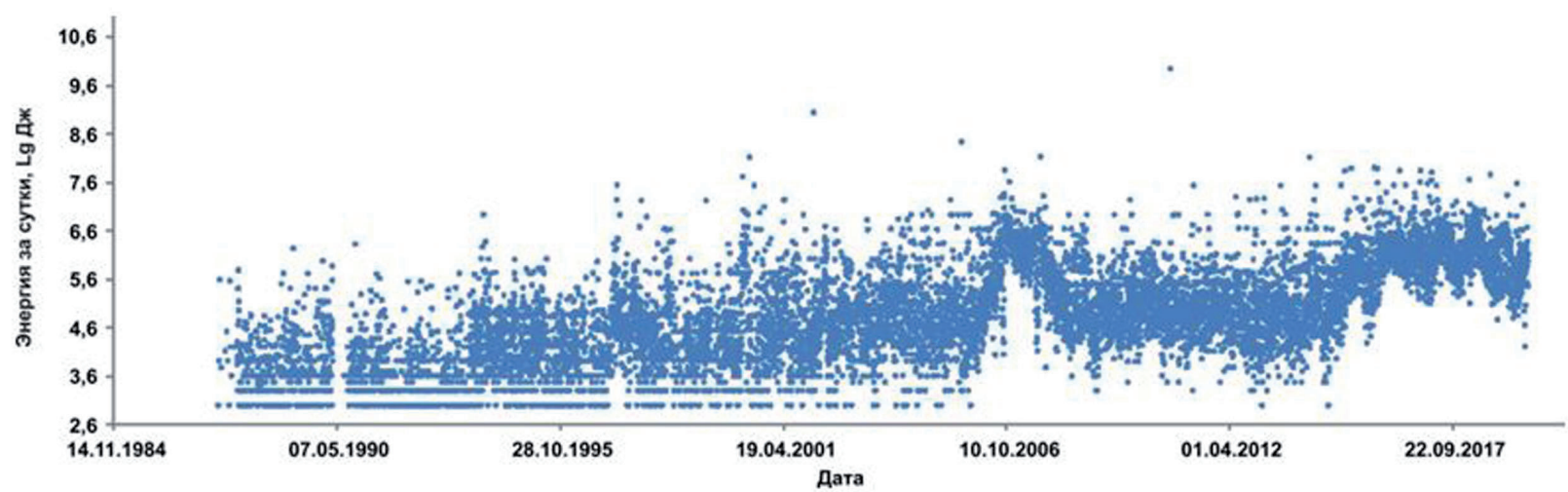

Рис. 4. Временной ряд сейсмичности (энергия событий в сутки) в районе рудника ОКР.

Fig. 4. Time series of seismicity (energy of events per day) in the area of the OKR mine.

на 1-ю и 3-ю четверти (см. рис. 6 (а) и (б)). Это соответствует ожиданиям, исходя из теоретических представлений о гравитационном воздействии Луны и Солнца в период сизигий.

На графиках по РР (см. рис. 5) влияние солнечно-лунных циклов также прослеживается, но оно заметно отличается от аналогичных графиков по ОКР (см. рис. 6). Для Расвумчоррского рудника график можно разделить по фазе полнолуния на 2 части. В первой части всплеск энергии при от- 

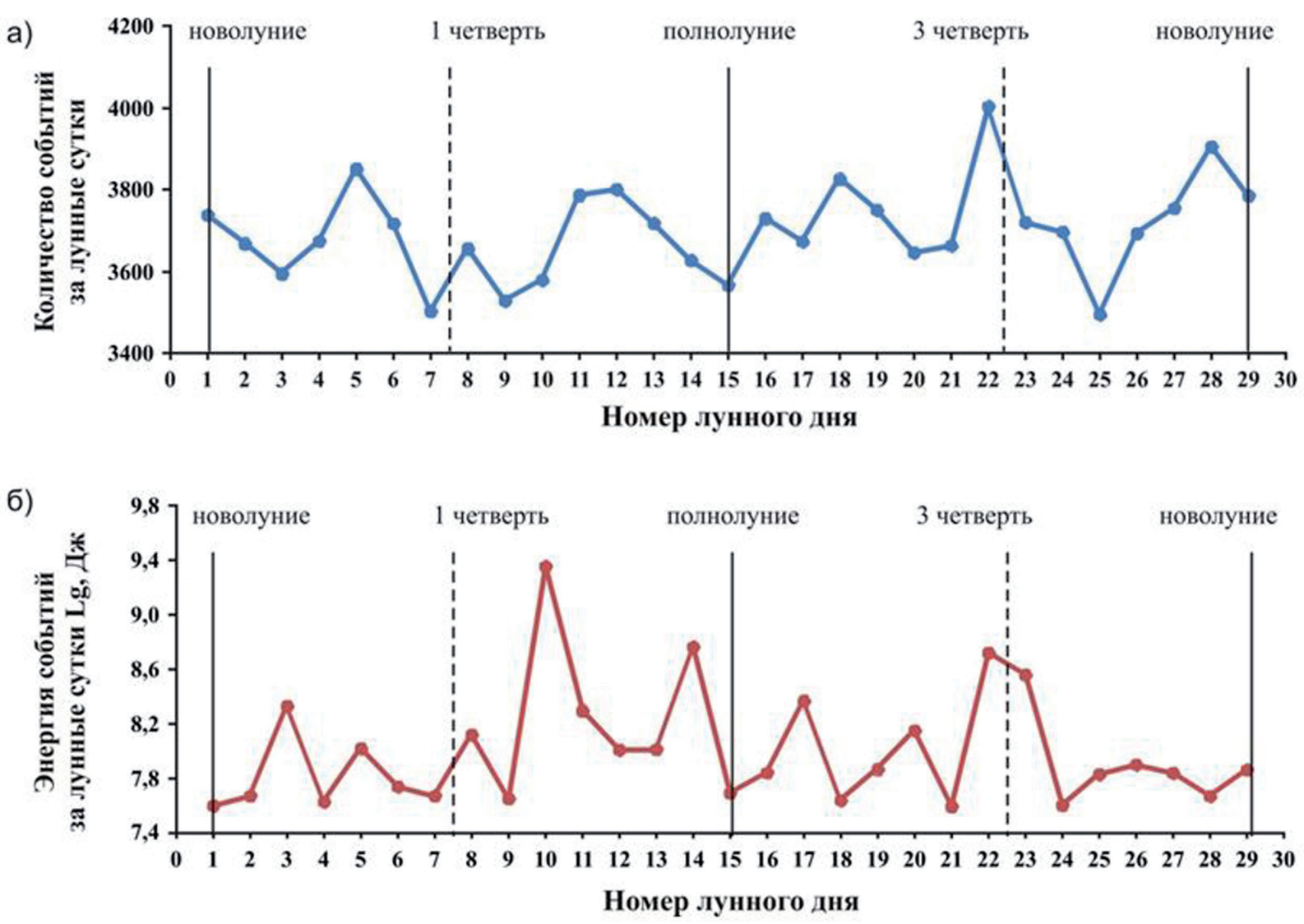

Рис. 5. График распределения количества сейсмических событий (а) и энергии (б) в зависимости от номера лунного дня в районе рудника РР.

Fig. 5. Graph of the distribution of the number of seismic events (a) and energy (b) depending on the number of lunar days in the RM mine area.

носительно низком значении количества событий приходится на 10-ый лунный день (см. рис. 5 б), что располагается ближе к 1 четверти, чем полнолунию. Это может объяснено высокой энергией отдельных событий. За 4-5 суток (5-ый лунный день) до максимума энергии наблюдается значительный пик количества событий при низких значениях энергии, которые мы интерпретируем как форшоки. К 7-му лунному дню количество событий падает до минимума в масштабе всего синодического месяца. Далее оба графика ведут себя синхронно вплоть до 10-го лунного дня, когда наблюдается резкий всплеск энергии. Количество афтершоков также имеет повышенные значения на протяжении 3-4 суток после пика выделения энергии. Во второй части лунного цикла имеются выраженные пики, как по энергии, так и по количеству событий, но в отличие от рассмотренной первой половины синодического месяца они совпадают и приходятся на 22-ой лунный день. При этом за 4-5 дней до максимума мы также наблюдаем повышенное количество событий, а после всплеска энергии количество событий резко падает к 25-му лунному дню. Таким образом, мы отмечаем различия в сейсмичности, как для разных рудников, так и в разных половинах синодического месяца для РР. Различия между характером сейсмичности рудников могут быть интерпретированы относительным поворотом структур месторождений на 15-20 А для объяснения различий в поведении сейсмичности РР в разных половинах синодического месяца предлагается рассмотреть склонение Луны. На одни и те же активные структуры в разные периоды лунного цикла она воздействует под разными углами. Для РР закономерности поведения сейсмичности в разных половинах синодического месяца имеют прогностическое значение, особенно для резкого всплеска на 10-ые лунные сутки, которым предшествует характерное поведение событий с малой энергией (резкий рост количества и быстрый спад до минимума). 

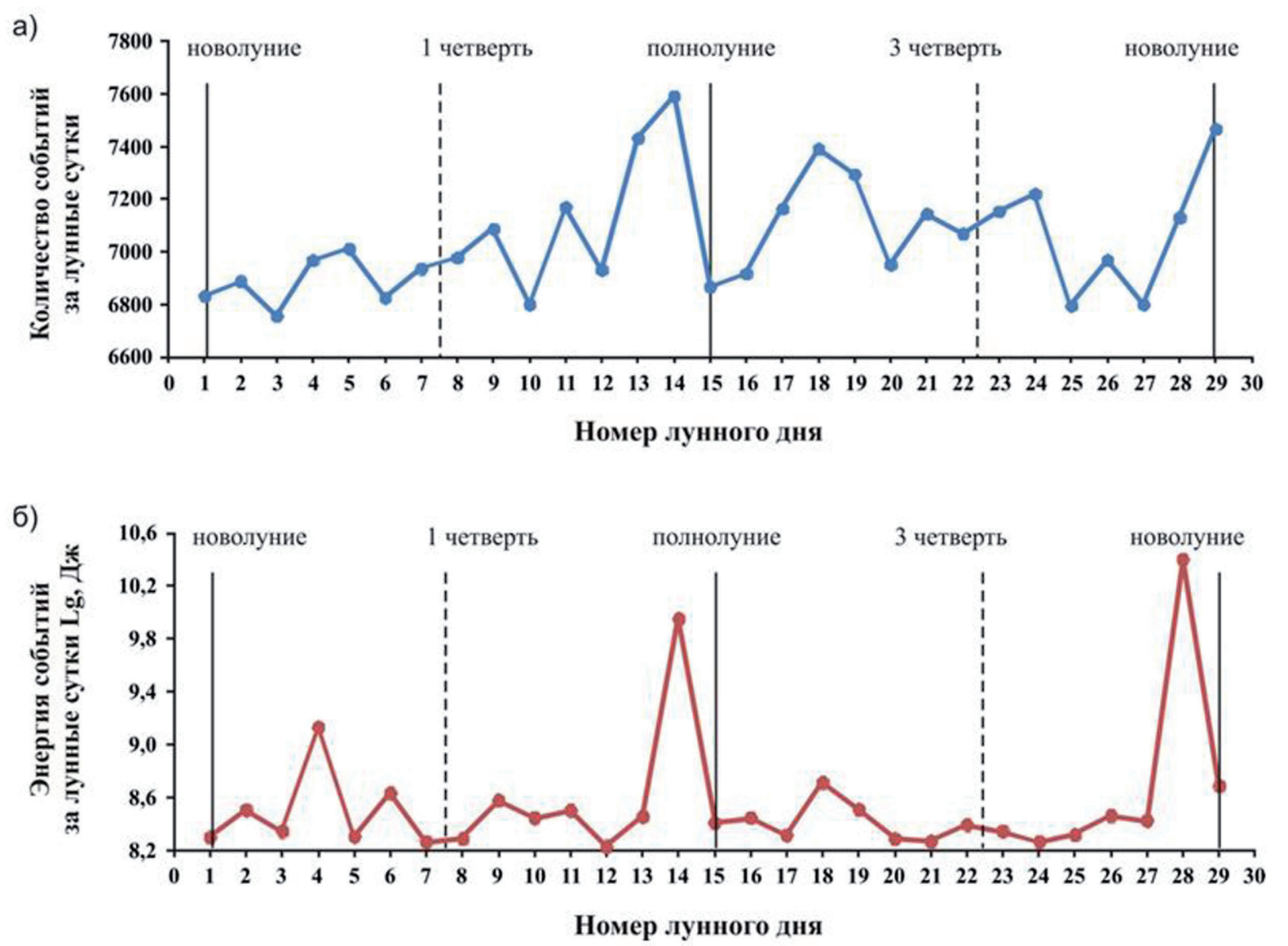

Рис. 6. График распределения количества сейсмических событий (а) и энергии (б) в зависимости от номера лунного дня ОКР.

Fig. 6. Graph of the distribution of the number of seismic events (a) and energy (b) depending on the number of lunar days in the area of the OKR mine.

Исследования выполнены в рамках раздела «Инновационные технологии и методы сбора, обработки и анализа геолого-геофизических данных в целях эффективного и безопасного освоения глубоких горизонтов месторождений стратегических полезных ископаемы» по НИР № 0226-2019-0053.

\section{Литература}

1. Астрономические явления до 2050 г. (под ред. Козловского А.Н.) Серия «Астробиблиотека». АстроКА, 2012. 292 с. (с изобр.). http://www.astronet.ru.

2. Климишин И.А. Календарь и хронология. 2-е изд., перераб. и доп. М. Изд-во: «Наука». Гл. ред. физикоматем. лит-ры. 1985. 320 с.

3. Zhirova A.M., Zhirov D.V. Sun-Moon tides and Induced Seismicity at the mines in the Khibiny massif (NE of the Fennoscandian shield) / Conference Proceedings The 19th International Multidisciplinary Scientific GeoConference \& EXPO (SGEM-2019), Albena (Bulgaria) 30 June - 06 July 2019. - Albena (Bulgaria), 2019. V. 19. Issue 1.1 Geology. Applied and Environmental Geophisics. P. 967-974. DOI: 10.5593/sgem2019/1.1. 